\title{
TRAINING PROGRAM FORDEVELOPMENT ENDURANCE PERFORMANCE AND ITS EFFECT ON SOME PHYSIOLOGICAL VARIABLES FOR WRESTLERS
}

\section{${ }^{1}$ Dr . Belal Morsy Mohammed Witwit}

\section{- Introduction and research problem}

Fitness is the key component of the rest of the ingredients needed to reach what is known (Sportive Form).Hanafi Mahmoud Mokhtar (1985) indicates that the player's fitness significantly affects his performance of skills; the better the physical attributes, he could use his skills and the implementation of his tactical duties, no matter how the player's technical skills and his proficiency of playing tactics, he will not be able to carry out those duties if he isn't qualified and fully physically prepared. (15:78)

AweysJabali (2000) added that wrestling is based on both the antenna and anaerobic energy system, but mainly the prevailing one is producing anaerobic energy system, while Hussein Fahmy (1993) believes that the importance of stamina of the wrestler in the application of the number of grabs during the game time when completed can be up to 15 grabs with high strength and the same for defense movements which are heavily high against the grabs of the striker wrestler and this requires a high level of muscular endurance of the wrestler. (17) (9:25)

Mohammed Allawi (1993) believes that endurance is divided into (strength endurance - speed endurance - periodic respiratory endurance - hard muscle tension endurance - stamina)asMuftiHammad (1998) defines it as the capacity to continue generating output power against resistances for a long period of time. (24:175) (21:128).

Fodor (1992) mentioned that the low stamina level of wrestler leads to weaken the capacity to continue to fight with high efficiency, the disruption of level of technical performance of the skills and the non-completion of the tactical duties successfully during the games, in addition to the negative impact upon the speed of recovery between games. (13:43)

JERMAN, HANLLY (1982) mentioned that the wrestler who is characterized by a high level of stamina can convert defeat into victory in the last minutes of the game, asFodor (1992) indicates that endurance of wrestling requires capacity to continue to exert force to the extent that guarantees the implementation of the skills and overcome resistance of the opponent until the end of the game, while Masnik et al. (1994) added that endurance enablesthewrestler from rapid repetition of maneuvers and maintain the speed of implementation of skills until the end of the game. (19:15) (13:41), (27:78)

All of Mohammad Hassan Allawi and Abdul Fattah Abu Ela (2000) believe that wrestling is a kind of sports in which the physical capacity play a key role, as well as development of aerobic and anaerobic capacity, upon which the wrestler depends in his specialized activity. (25:127).

\footnotetext{
${ }^{1}$ Lecturer, Department of the fights and water sports in College physical education - University of Sadat City
} 
AweysJabali (2000) believes that wrestling is based on both the antenna and anaerobic energy system, but mainly the prevailing one is producing anaerobic energy system. (9:25)

Continuation in fighting requires the capacity to efficiently implement the attacking skills while retaining the high functional efficiency until the end of the game, which makes endurance one important physical attributes in wrestling, as MARTEN, MARGHERITA(1999)mentioned that endurance is one of the necessary physical requirements for the continuation in fighting successfully during the games.(31)(20:117)

Special endurance is the fundamental basis of the capacity of the wrestler to counter fatigue resulting from the impact of the special training loads or competitions, as Mohammad Reza Ruby (1986), quoting SHELBILOV KILMEN mentioned that the capacity of the wrestler to counter fatigue during training and competition and the high stability of the use of skill and tactical abilities during the games reflects the special endurance level he has. (23) (26:4)

Wrestling is one of sports in which the player is under high load in the game as performance intensity is high and accompanied by large effort on the organs of the body and the continuation of this effort through the game time lead to the exposure of the player to fatigue and stress and drop in the player physical, technical and tactical abilities and the inability to continue to perform at the same strength of the beginning of the game.

Research problem is that through researcher experience in wrestling, under amendments to the law so that the game consists of three rounds of 2 minutes with 30second rest in between and each game does have its own result, he noted the inability of the players to continue to fight efficiently, the disruption of technical, physical and tactical performance level, the inability to overcome the resistance of the opponent, the emergence of signs of fatigue and stress, drop in the player abilities and the inability to continue to perform at the same strength of the beginning of the game. The researcher believes that it may be due to several factors, including poor stamina level and the lack of its development of many of the players, which affect the results of games. From the above, it was necessary to develop a training program on scientific basis for the development of stamina and knowledge of its impact on anaerobic capacity and some physiological variables.

- Research objectives:

Setting training program FOR Development endurance performance and its effect on:-

1- Identifying the extent of the impact of the training program on stamina and the most effective physical elements on it among the members of the research sample.

2- Identifying the impact of the training program on the level of anaerobic capacity and some physiological variables of the research among the members of the research sample.

- Research hypotheses: 
1- There are significant statistical differences between the measurements (pre and post) of the members of the sample in stamina and the most effective physical elements on it in the direction of the post measurement.

2- There are significant statistical differences between the measurements (pre and post) in anaerobic capacity and some physiological variables of the research in the direction of the post measurement.

\section{- Research Terms:}

1- Stamina: it is the ability of endurance to repeat of implementation of technical skills for long time without feeling fatigue. (2:66)

2- Anaerobic capacity: It's the muscle's ability to work within the framework of the anaerobic energy production. $(35: 196)$

\section{1- Method}

The researcher used the experimental method as it suits the research nature by using the experimental design with pre and post measurements on an experimental set.

\section{2- Research Sample}

The Research Sample was chosen intentionally from the U-20 players of Menofia area team (third stage) in 2011-2012 season and the players registered in the Egyptian Wrestling Federation. The research community was 18 wrestlers while only 8Distinguished playerswere chosen to do surveys upon so the basic study was applied on 10 wrestlers.and 8 Non-distinguished playersisn't distinguished and it is outside the basic sample, Table (1) shows the homogeneity of the sample in (growth - physical physiological) variables.

\section{Table (1)}

\section{The homogeneity of the sample in (growth - physical - physiological)variables $n=18$}

\begin{tabular}{|c|c|c|c|c|c|c|}
\hline \multicolumn{2}{|c|}{ Variables } & Units & Mean & St.Div & Median & Skewness \\
\hline \multicolumn{2}{|c|}{$\mathrm{Age}$} & year & 19.11 & 0.68 & 19 & -0.13 \\
\hline \multicolumn{2}{|r|}{ Height } & $\mathrm{Cm}$ & 174.28 & 3.61 & 174.5 & 0.32 \\
\hline \multicolumn{2}{|r|}{ Weight } & $\mathrm{Kg}$ & 77.78 & 11.47 & 77.5 & -0.01 \\
\hline \multicolumn{2}{|r|}{ Training Age } & Year & 7.39 & 0.98 & 7.5 & -0.07 \\
\hline \multirow[t]{2}{*}{ Endurance } & Speed & Reps & 17.44 & 1.76 & 17.5 & -0.34 \\
\hline & Strength & Reps & 10.39 & 1.46 & 10 & -0.01 \\
\hline \multirow{2}{*}{$\begin{array}{l}\text { endurance } \\
\text { performance }\end{array}$} & Rep. in 2 min & Reps & 26.94 & 2.04 & 27 & -0.06 \\
\hline & Time to return $120 \mathrm{sec} / \mathrm{min}$ & Pulse & 3.56 & 0.42 & 3.6 & 0.5 \\
\hline \multicolumn{2}{|r|}{ Pulse rate at rest } & $\mathrm{pulse} / \mathrm{min}$ & 67.83 & 1.92 & 68 & 0.21 \\
\hline \multicolumn{2}{|r|}{ Anaerobic Capacity } & $\mathrm{Kg} \mathrm{m} / \mathrm{sec}$ & 64.83 & 7.69 & 64.05 & 0.39 \\
\hline \multirow{3}{*}{$\begin{array}{c}\text { Carlson } \\
\text { Fatigue } \\
\text { Curve }\end{array}$} & Production degree (steps) & Degree & 9.06 & 0.8 & 9 & -0.11 \\
\hline & Degree of pulse speed & Degree & 11.83 & 1.15 & 12 & 0.1 \\
\hline & $\begin{array}{l}\text { Level of fitness cardio- } \\
\text { vascular system }\end{array}$ & Degree $\%$ & 59.33 & 2.4 & 59 & -0.13 \\
\hline \multirow{2}{*}{$\begin{array}{l}\text { Respiratory } \\
\text { System } \\
\text { Efficiency }\end{array}$} & FEV1 & Liter & 2.78 & 0.16 & 2.8 & -0.52 \\
\hline & FVC & Liter & 2.93 & 0.26 & 3 & 2.11 \\
\hline \multicolumn{2}{|c|}{ Anaerobic Efficiency 8 seconds on the } & (Watts) in & 391.72 & 26.6 & 392.5 & 0.26 \\
\hline
\end{tabular}


Table (1) shows that the torsion modulus in physical variables was limited between $(-3:+3)$ which shows the homogeneity of the sample members in these variables.

\section{- Tools and equipment used in data collection:}

\section{1- Reference Survey:}

The researcher conducted a survey of studies and scientific references that dealt stamina within the limits available to researcher for the purpose of identification and how to develop a program, the formation of weights and to benefit from its results in discussing the results of the current study, as well as determine the tests used in the measurement and also to identify the anaerobic capacity and associated physiological variables.

\section{2- Questionnaire (attachment 2)}

The researcher has designed a questionnaire (attachment 1) to solicit the views of experts in the field of study variables through personal interviews to determine the most influential fitness elements in stamina and physiological variables required and to determine the appropriate tests for measurement, in the period from 1/1/2011 to 30/1/2011 AD where additions and deletions have been taken into account to suit with the experts opinion.

\section{3- Tests used in research (attachment 4)}

Speed endurance - Strength endurance - endurance performance(23) - Anaerobic Capacity (3) - CarlsonFatigue Curve - Vital Capacity - Anaerobic Efficiency

\section{4- Equipment used in research}

Electronic scales to measure weight to the nearest $\mathrm{kg}$ - Restmeter to measure lengths to the nearest $\mathrm{cm}$ - Measuring bar to measure distances - Stopwatch to measure the time per second and to the nearest 0.01 of second -WrestlingMat-multi weights Wrestling Bodies - Polar watches - Ergometric bike-Spirometer - 3-Kg medicine ball.

\section{5- Data registration form (attachment 3)}

Training Program (attachment 5, 6, 7, 8, 9, 10)

The training program has been prepared by following these steps:

- The researcher conducted a survey of Arabic and Foreign books within the limits available to researcher.

- The researcher conducted a survey of researches and studies related to the research variables.

- Meeting the experts in wrestling.

- The main objective of the program

The program aims to develop the stamina of wrestlers and to identify the impact of this program on the anaerobic capacity and some physiological variables.

\section{- The basis of programs development}

a) Developing programs according to scientific basis.

b) The training program shall suit the established objectives. 
c) The training program and its contents shall suit the age range of the chosen sample.

d) Program flexibility and its ability to be modified.

e) Benefit from the previous studies that developed training programs.

f) The continuity and regularity in the exercise of the training program to get the desired benefit.

g) Taking into account the principles and foundations of training in the development and writing of the training program training units such as (warm-up - the main part - closing).

h) Taking into account the individual differences when developing the program.

\section{The determinants of the training program}

\section{- The period of implementation of the program}

The training program will be implemented in the preparation period and before the competitions. The application period of the program has been defined to be (12 weeks) and the total time of the program is (5760 minutes) which means (96 hours).

- Unit duration is 120 minutes.

- Weekly training units are 4 units.

- Training methods used (periodic both high and low - rep.)

- Formation of the training load.

The researcher used ripple method in the formation of load during program as he used:

$\checkmark$ Formation (2-1) and (1-1) in the preparation period.

$\checkmark$ Formation (1-1) before the competitions.

As the maximum intensity reached $95-100 \%$, the intensity lower than the maximum 85 94\%, high intensity 75-84\% medium intensity $65-74 \%$, and low-intensity 50-64\%.

\section{- Training Unit Parts}

Training Unit consists of the following parts respectively (warm-up as $15 \%$ then the main part as $80 \%$ including (skills then physical) then closing as 5\%).(11)(12)(10)(23)

\section{1- Warm-up}

This part of the training unit is primarily designed to prepare the player in all respects for the main part of the unit, working on giving muscle flexibility and elasticity needed, working on raising the body temperature and the preparation to perform the dynamic skills, try to maximize responsiveness ability of reaction and to focus on a review of skills path which will be performedlater.

\section{The main part prepared as follows (skills training then physical preparation)}

\section{2- Skills training}

This part of the unit contains workouts for development stamina by skill and tactical performance in light of the time and working on delaying fatigue and the development of anaerobic capacity. This part contains individual and coupleworkouts in which the muscular work is similar to skill performance requirements and at the same kinetic path, competitive matches and training with different weightbodies and withdifferent weight players.

\section{3- Physical preparation}


This part includes exercises for the development of stamina through special workouts then public ones, which include couple and individual exercises aimed at performance for the longest possible time without feeling tired in the light of the performance time.

\section{4- Closing}

This part of the training unit is designed to try to return the player to normal or close to it as possible, after the effort made, by using relaxation exercises with low loads.

\section{Rationing of training loads:}

To determine the maximum pulse rate, we use the following equation:

Maximum pulse rate $=220-$ age $=\ldots \ldots \ldots .$. Pulse $/ \mathrm{min}$

The reserves of the maximum rate of the pulse $=$ Maximum pulse rate - pulse rate at rest $=\ldots$. Pulse/min

Training pulse rate $=($ The reserves of pulse $\times$ target intensity/100 $)+$ pulse rate at rest $)$.

For rationing of training loads, we followed the following:

Determination of average pulse rate at rest for the sample $68 \mathrm{pulse} / \mathrm{min}$.

Determination of the average age of the sample (19 years).

Maximum pulse rate $=220$ - average age

Maximum pulse rate $=220-19=201 \mathrm{pulse} / \mathrm{min}$.

The reserves of pulse $=$ Maximum pulse rate - pulse rate at rest

The reserves of pulse $=201-68=133 \mathrm{pulse} / \mathrm{min}$.

For rationing of training loads by using pulse rate, we follow the following equation:

Training pulse rate at $90 \%=(133 \times 90 \%)+68=188 \mathrm{pulse} / \mathrm{min}$.

Rationing of training loads by using pulse rate

(Maximum load)

(Load less than maximum)

(High load)

(Moderate load) percentage 95:100\%

percentage $85: 94 \%$

percentage $75: 84 \%$

percentage $65: 74 \%$
Pulse rate 194:201 pulse/min

Pulse rate 181:193 pulse/min

Pulse rate 168:180 pulse/min

Pulse rate 154:166 pulse/min

Table (2)

Basis of load formation based on

performance time according to Energy Production Systems

\begin{tabular}{|c|c|c|c|c|c|c|}
\hline $\begin{array}{l}\text { Energy } \\
\text { System }\end{array}$ & $\begin{array}{l}\text { Exercise } \\
\text { period }\end{array}$ & $\begin{array}{l}\text { Exercise } \\
\text { reps }\end{array}$ & No. of Sets & $\begin{array}{l}\text { No. of exercise } \\
\text { reps in set }\end{array}$ & $\begin{array}{c}\text { exercise : } \\
\text { rest }\end{array}$ & Rest type \\
\hline ATP - PC & $\begin{array}{l}10 \mathrm{sec} \\
15 \mathrm{sec} \\
20 \mathrm{sec} \\
25 \mathrm{sec}\end{array}$ & $\begin{array}{l}50 \\
45 \\
40 \\
32\end{array}$ & $\begin{array}{l}5 \\
5 \\
4 \\
4\end{array}$ & $\begin{array}{c}10 \\
9 \\
10 \\
8\end{array}$ & $1: 3$ & $\begin{array}{l}\text { active rest } \\
\text { (walking } \\
\text { and } \\
\text { stretches) }\end{array}$ \\
\hline $\begin{array}{l}\text { ATP-PC, } \\
\text { LA }\end{array}$ & $\begin{array}{c}30 \mathrm{sec} \\
40-50 \mathrm{sec} \\
60-70 \mathrm{sec} \\
80 \mathrm{sec}\end{array}$ & $\begin{array}{l}25 \\
20 \\
15 \\
10\end{array}$ & $\begin{array}{l}5 \\
4 \\
3 \\
2 \\
\end{array}$ & $\begin{array}{l}5 \\
5 \\
5 \\
5\end{array}$ & $1: 3$ & $\begin{array}{c}\text { light to } \\
\text { moderate } \\
\text { exercises } \\
\text { and Jogging }\end{array}$ \\
\hline $\mathrm{LA}, \mathrm{O}_{2}$ & $\begin{array}{c}1.3-2 \mathrm{~min} \\
2.1-2.4 \mathrm{~min} \\
2.5-3 \mathrm{~min}\end{array}$ & $\begin{array}{l}8 \\
6 \\
4\end{array}$ & $\begin{array}{l}2 \\
1 \\
1\end{array}$ & $\begin{array}{l}4 \\
6 \\
4\end{array}$ & $\begin{array}{l}1: 2 \\
1: 1\end{array}$ & $\begin{array}{c}\text { light to } \\
\text { moderate } \\
\text { exercises }\end{array}$ \\
\hline
\end{tabular}




\section{- Surveys}

The researcher selected a random sample of the research community of (8) players outside the basic sample, and he conducted tests on them with the help of assistants, on $5: 7 / 2 / 2011$ AD.

\section{Study Objective}

- Ensure the safety of the implementation and application of measurements and tests, validity of equipment and tools and related procedures in accordance with the conditions set for them and the suitability of the place.

- Determine the time required for measurement and the time each player takes at each test for measurement.

- Identify the mistakes that we could make during the implementation of tests and measurements and arrange its conduct and their suitability for the age range.

We ensurethe appropriate tests to sample as well as the tools and the place of the measurements, as well as to ensure familiarity of assistants on how to conduct the tests in order to avoid measurement errors.

\section{- Scientific coefficients for tests used}

1- Test sincerity

The researcher calculated sincerity of distinction between two groups; one isn't distinguished and it is outside the basic sample while the other is distinguished (surveyed) and each of them consisted of (8) wrestlers.

Table (3)

Indication of the differences between the two groups (distinguished and nondistinguished) in the tests of the research $\quad n=16$

\begin{tabular}{|c|c|c|c|c|c|c|c|}
\hline & \multirow{2}{*}{ Variables } & \multirow{2}{*}{ Units } & \multicolumn{2}{|c|}{$\begin{array}{c}\text { Distinguished } \\
\mathrm{n}=8\end{array}$} & \multicolumn{2}{|c|}{$\begin{array}{l}\text { Non-distinguished } \\
n=8\end{array}$} & \multirow[t]{2}{*}{ T Test } \\
\hline & & & Mean & St.Div & Mean & St.Div & \\
\hline \multirow{2}{*}{ Endurance } & Speed & Reps & 10.13 & 1.46 & 6 & 93 & $6.76^{*}$ \\
\hline & Strength & Reps & 17 & 2 & 13.13 & 1.25 & $4.65^{*}$ \\
\hline \multirow{2}{*}{$\begin{array}{l}\text { endurance } \\
\text { performance }\end{array}$} & Rep. & Reps & 25.88 & 1.96 & 19.13 & 1.55 & $7.64 *$ \\
\hline & Time to return 120 pulse / min & $\min$ & 3.33 & 0.31 & 4.6 & 0.76 & $11.45^{*}$ \\
\hline \multicolumn{2}{|c|}{ Anaerobic Capacity } & $\mathrm{Kg} \mathrm{m} / \mathrm{sec}$ & 63.94 & 7.64 & 56.83 & 4.78 & $2.23 *$ \\
\hline \multirow{3}{*}{$\begin{array}{l}\text { Carlson } \\
\text { Fatigue } \\
\text { Curve }\end{array}$} & Production degree (steps) & Degree & 8.5 & 0.54 & 11.75 & 0.46 & $13^{*}$ \\
\hline & Degree of pulse speed & Degree & 12.25 & 1.04 & 14.5 & 0.53 & $5.46^{*}$ \\
\hline & $\begin{array}{l}\text { Level of fitness cardio- } \\
\text { vascular system }\end{array}$ & Degree \% & 59.5 & 2.33 & 48.5 & 1.77 & $10.63 *$ \\
\hline
\end{tabular}

The value of "T" from table is $(2.145)$ at $(0.05)$

Shown in Table (3) the presence of statistically significant differences in favor of distinguishedgroup, which refers to the sincerity of the tests.

\section{Tests stability}

The researcher calculated tests stability using re-testing on a sample of (8) wrestlers of the third stage players and during $14: 16 / 2 / 2011$ ADafter a week as interval between the two applications. 
Table (4)

The arithmetic mean, standard deviation and coefficient of correlation between the first application and the second application of physical tests under discussion for the exploratory $n=(8)$

\begin{tabular}{|c|c|c|c|c|c|c|c|}
\hline \multirow{2}{*}{ Variables } & & \multirow{2}{*}{ Unit } & \multicolumn{2}{|c|}{ first application } & \multicolumn{2}{|c|}{ second application } & \multirow[t]{2}{*}{$\mathbf{R}$} \\
\hline & & & Mean & St.Div & Mean & St.Div & \\
\hline \multirow{2}{*}{ Endurance } & Speed & Reps & 10.13 & 1.46 & 10.75 & 1.16 & 0.95 \\
\hline & Strength & Reps & 17 & 2 & 17.5 & 2.27 & 0.88 \\
\hline \multirow{2}{*}{$\begin{array}{l}\text { endurance } \\
\text { performance }\end{array}$} & Rep. & Reps & 25.88 & 1.96 & 26.5 & 1.31 & 0.92 \\
\hline & $\begin{array}{l}\text { Time to return } 120 \\
\text { pulse / min }\end{array}$ & $\min$ & 3.33 & 0.31 & 3.34 & 0.26 & 0.99 \\
\hline \multicolumn{2}{|c|}{ Anaerobic Capacity } & $\mathrm{Kg} \mathrm{m} / \mathrm{sec}$ & 63.94 & 7.64 & 65.46 & 7.94 & 0.99 \\
\hline \multirow{3}{*}{$\begin{array}{l}\text { Carlson } \\
\text { Fatigue } \\
\text { Curve }\end{array}$} & Rep (steps) & Degree & 8.5 & 0.54 & 8.5 & 0.53 & 0.78 \\
\hline & pulse speed & Degree & 12.25 & 1.04 & 12 & 0.76 & 0.73 \\
\hline & $\begin{array}{l}\text { Level of fitness cardio- } \\
\text { vascular system }\end{array}$ & Degree $\%$ & 59.5 & 2.33 & 60 & 1.85 & 0.74 \\
\hline
\end{tabular}

The tabulated value of " $R$ " (0.707) at significance level (0.05)

As reflected in the table (4), the value of calculated " $R$ " is greater than the tabulated " $R$ " which indicates the stability of tests under discussion.

- Pre Measurements: Pre measurements were conducted on14 :16/2/2011 AD for the sample individuals and physiological measurements has been done at physiological measurements laboratory - Faculty of Physical Education - Sadat City, measuring devices were calibrated and ensured its safety.

- Implementation of the program: The proposed program was applied in the period from 26/2/2011 to 20/5/2011 AD.

- Post Measurements: Post measurements were conducted on 21:23/5/2011 m with the same terms and conditions of Pre measurement and at the same place.

The statistical processing:

The researcher used the following statistical operations for the processing of data in this study:

- The arithmetic mean - standard deviation - the median - torsion modulus

-Correlation coefficient - ETA 2coefficient - T test - the percentage of improvement 


\section{Presentation and discussion of the results:}

First, to present and discuss the results of the first hypothesis: -

Table (5)

Indication of the differences between the (pre/post) measurement for research group in stamina and strength endurance and speed endurance $\mathbf{n}=(10)$

\begin{tabular}{|c|c|c|c|c|c|c|}
\hline \multicolumn{2}{|r|}{ Variables } & \multicolumn{2}{|c|}{ Pre } & \multicolumn{2}{|c|}{ Post } & \multirow[t]{2}{*}{ T Test } \\
\hline & & Mean & St.Div & Mean & St.Div & \\
\hline \multirow{2}{*}{$\begin{array}{l}\text { endurance } \\
\text { performance }\end{array}$} & Rep. in 2 min & 27.8 & 1.75 & 34 & 1.63 & $46.5 *$ \\
\hline & Time to return $120 \mathrm{sec} / \mathrm{min}$ & 3.75 & 0.42 & 2.99 & 0.32 & $13.53 *$ \\
\hline \multicolumn{2}{|c|}{ strength endurance } & 17.8 & 1055 & 22.4 & 1.51 & $28.17 *$ \\
\hline \multicolumn{2}{|c|}{ speed endurance } & 10.6 & 1.51 & 14.9 & 1.1 & $20.15 *$ \\
\hline
\end{tabular}

The tabulated value of "T" (1.833) at significance level (0.05)

Shown in Table (5) the presence of statistically significant differences between pre and post measurements for the experimental group in favor of post measurements in stamina variables (rep - Time to return $120 \mathrm{sec} / \mathrm{min}$ ), strength enduranceand speed enduranceas the calculated " $T$ " value is higher than the tabulated value of " $T$ " for all variables.

Table (6)

Value of the impact of the program "ETA 2" and the percentage of improvement between (pre / post) measurements for the research group in stamina and speed endurance and strength endurance $n=(10)$

\begin{tabular}{|c|c|c|c|c|c|c|c|c|}
\hline \multicolumn{2}{|c|}{ Variables } & \multicolumn{2}{|c|}{ Pre } & \multicolumn{2}{|c|}{ Post } & \multirow[t]{2}{*}{ ETA $^{2}$} & \multirow{2}{*}{$\begin{array}{l}\text { percentage of } \\
\text { improvement }\end{array}$} & \multirow{2}{*}{$\begin{array}{l}\text { At the } \\
\text { direction of }\end{array}$} \\
\hline & & Mean & St.Div & Mean & St.Div & & & \\
\hline \multirow{2}{*}{$\begin{array}{l}\text { endurance } \\
\text { performan } \\
\text { ce }\end{array}$} & Rep. in 2 min & 27.8 & 1.75 & 34 & 1.63 & 0.99 & $22.3 \%$ & Post \\
\hline & $\begin{array}{l}\text { Time to return } \\
120 \mathrm{sec} / \mathrm{min}\end{array}$ & 3.75 & 0.42 & 2.99 & 0.32 & 0.97 & $20.3 \%$ & Post \\
\hline \multicolumn{2}{|c|}{ strength endurance } & 17.8 & 1055 & 22.4 & 1.51 & 0.99 & $25.8 \%$ & Post \\
\hline \multicolumn{2}{|c|}{ speed endurance } & 10.6 & 1.51 & 14.9 & 1.1 & 0.99 & $40.6 \%$ & Post \\
\hline
\end{tabular}

The results of the table (6) indicates that the value of (ETA 2) ranged between $(0.97$, 0.99) which shows the strength of the impact of the proposed program to the stamina and strength endurance and speed endurance of the research group and percentage of improvement ranged between $(20.3 \%, 40.6 \%)$ for the (pre / post) measurements for the research group in stamina and speed endurance and strength endurance in the direction of the post measurement.

Evaluation of ETA 2 coefficient

(From zero to less than $0.3=$ weak effect), (from 0.3 to less than $0.5=$ Medium effect) (From 0.5 to one $=$ strong effect)

\section{Discussion of results of the first hypothesis: -}

In light of the previous presentation of the results of the first hypothesis reached by the researcher in the framework of the objectives and research hypotheses and guided by the results of previous studies and what is mentioned in scientific references, the researcher begins to discuss those results as follows: 
Shown in Table (5) the presence of statistically significant differences between pre and post measurements for the experimental group in stamina variables (rep - Time to return $120 \mathrm{sec} / \mathrm{min}$ ), strength enduranceand speed endurance in favor of post measurements as the tabulated value of " $T$ " at (0.05) lower than the calculated " $T$ " value. Differences were as follows: in stamina test (rep - time to return $120 \mathrm{sec} / \mathrm{min}$ ), the calculated " $T$ " value $(46.5,13.53)$ and in strength endurance test, the calculated " $T$ " value (18.17) and in speed endurance test, the calculated "T" value (20.15).

Shown in table (6) that the value of (ETA 2) the calculated strength of the impact of the proposed program ranged between $(0.97,0.99)$ which shows that the proposed program has a great impact and the established exercises were effective in terms of development of stamina and strength endurance and speed endurance. This program was on scientific basis and contains individual and couple workouts in which the muscular work is similar to skill performance requirements and at the same kinetic path which had a great impact on these variables.

Shown in table (6) that there are percentages of improvement between pre and post measurements for stamina (rep - Time to return $120 \mathrm{sec} / \mathrm{min}$ ),strength enduranceand speed endurance in favor of post measurements. The percentages of improvement for stamina (rep - Time to return $120 \mathrm{sec} / \mathrm{min}$ ) ranged between $(20.3 \%, 40.6 \%)$ and for speed endurance $(40.6 \%)$ and for strength endurance $(25.8 \%)$

The researcher believes that this improvement (change) due to the proposed training program for the development of stamina, and it was due to the transfer of the impact of training to physical variables, in addition to the regularity of the players and their commitment in training, and that the improvement was the result of suitable selected exercises with wrestling and age range using the bodies and colleague as well to skill training and competitive wrestling in addition to using periodic and rep. training methodsandthis indicates the wrestler need them. These results are consistent with the study of Al-SayedKandil (2003)(8), Hassan Mahfouz (1994)(16) and Mohammed Reza Ruby (1986)(26) that the improvement of the results of speed endurance test of wrestling (performing bridge skill for $30 \mathrm{sec}$ ) is due to the impact of the training program including workouts for colleague and bodies in addition to apply periodic training method that work on increasing anaerobic capacity for wretlers.

These results are consistent with Al sayed Abdel-Maksoud (1994) that directed training for the development of some physical characteristics can contribute in the development of some other physical characteristics, and that is known as the transmission of positive effect of the training. (7:311)

In view of the above in the table (4), (8) so the first hypothesis has been achieved, which indicates the presence of statistically significant differences between the two (pre / post) measurements for the research sample members in stamina and elements affecting it in the direction of the post measurement. 
Secondly, presentation and discussion of the results of the second hypothesis: 1-Presenting the results the second hypothesis

Table (7)

Indication of the differences between the (Pre / Post) measurements for the research group in anaerobic capacity and physiological variables under discussion $\mathbf{n}=(\mathbf{1 0})$

\begin{tabular}{|c|c|c|c|c|c|c|}
\hline \multirow{2}{*}{\multicolumn{2}{|c|}{ Variables }} & \multicolumn{2}{|c|}{ Pre } & \multicolumn{2}{|c|}{ Post } & \multirow[t]{2}{*}{ T Tesi } \\
\hline & & Mean & St.Div & Mean & St.Div & \\
\hline \multicolumn{2}{|r|}{ Pulse rate at rest } & 67.9 & 1.66 & 62.8 & 1.03 & $16.22 *$ \\
\hline \multicolumn{2}{|r|}{ Anaerobic Capacity } & 65.56 & 8.07 & 71.25 & 8.62 & $5.9 *$ \\
\hline \multirow{3}{*}{$\begin{array}{c}\text { Carlson } \\
\text { Fatigue Curve }\end{array}$} & Production degree (steps) & 9.4 & 0.84 & 5.8 & 0.63 & $11.78 *$ \\
\hline & Degree of pulse speed & 11.5 & 1.18 & 9.5 & 1.18 & $13.42 *$ \\
\hline & Level of fitness cardio-vascular syste & 59.2 & 2.57 & 70.4 & 1.9 & $16.47 *$ \\
\hline \multirow{2}{*}{$\begin{array}{l}\text { Respiratory } \\
\text { System } \\
\text { Efficiency }\end{array}$} & FEV1 & 2.78 & 0.18 & 3.72 & 0.34 & $10.85 *$ \\
\hline & FVC & 2.91 & 0.32 & 4.1 & 0.27 & $19.68 *$ \\
\hline \multicolumn{2}{|c|}{ Anaerobic Efficiency 8 seconds on the ergometric bike } & 396.9 & 31.91 & 490 & 33.67 & $15.46 *$ \\
\hline
\end{tabular}

The tabulated value of "T" (1.833) at significance level (0.05)

The results of the table (7) indicate the presence of statistically significant differences between the (Pre / post) measurements for the research group in anaerobic capacity and physiological variables under discussion in the direction of the post measurement.

Table (8)

The value of the impact of the program "ETA 2 " and the percentage of improvement between the (pre / post) measurements for the research group in anaerobic capacity and physiological variables under discussion $n=(10)$

\begin{tabular}{|c|c|c|c|c|c|c|c|c|}
\hline \multirow{2}{*}{\multicolumn{2}{|c|}{ Variables }} & \multicolumn{2}{|c|}{ Pre } & \multicolumn{2}{|c|}{ Post } & \multirow{2}{*}{ ETA $^{2}$} & \multirow{2}{*}{$\begin{array}{l}\text { percentage of } \\
\text { improvement }\end{array}$} & \multirow{2}{*}{$\begin{array}{c}\text { At the } \\
\text { direction of }\end{array}$} \\
\hline & & Mean & St.Div & Mean & St.Div & & & \\
\hline \multicolumn{2}{|c|}{ Pulse rate at rest } & 67.9 & 1.66 & 62.8 & 1.03 & 0.98 & $7.5 \%$ & Post \\
\hline \multicolumn{2}{|c|}{ Anaerobic Capacity } & 65.56 & 8.07 & 71.25 & 8.62 & 0.85 & $8.68 \%$ & Post \\
\hline \multirow{3}{*}{$\begin{array}{l}\text { Carlson } \\
\text { Fatigue } \\
\text { Curve }\end{array}$} & Rep (steps) & 9.4 & 0.84 & 5.8 & 0.63 & 0.96 & $38.3 \%$ & Post \\
\hline & pulse speed & 11.5 & 1.18 & 9.5 & 1.18 & 0.97 & $17.4 \%$ & Post \\
\hline & $\begin{array}{c}\text { Level of fitness } \\
\text { cardio-vascular } \\
\text { system }\end{array}$ & 59.2 & 2.57 & 70.4 & 1.9 & 0.98 & $18.92 \%$ & Post \\
\hline \multirow{2}{*}{$\begin{array}{l}\text { Respiratory } \\
\text { System } \\
\text { Efficiency }\end{array}$} & FEV1 & 2.78 & 0.18 & 3.72 & 0.34 & 0.95 & $33.81 \%$ & Post \\
\hline & FVC & 2.91 & 0.32 & 4.1 & 0.27 & 0.98 & $40.89 \%$ & Post \\
\hline \multicolumn{2}{|c|}{$\begin{array}{c}\text { Anaerobic Efficiency } 8 \\
\text { seconds on the ergometric bike }\end{array}$} & 396.9 & 31.91 & 490 & 33.67 & 0.98 & $23.46 \%$ & Post \\
\hline
\end{tabular}

The results of the table (8) indicates that the value of (ETA 2) ranged between $(0.85$, 0.98) which shows the strength of the impact of the proposed program to anaerobic capacity and physiological variables under discussion for the research group and percentage of improvement ranged between $(7.5 \%, 40.89 \%)$ for the (Pre / Post) measurements for the research group in anaerobic capacity and physiological variables under discussion in the direction of the Post measurement. 
Evaluation of ETA 2 coefficient

(From zero to less than $0.3=$ weak effect), (from 0.3 to less than $0.5=$ Medium effect) (From 0.5 to one $=$ strong effect)

\section{Discussion of results of the first hypothesis: -}

In light of the previous presentation of the results of the first hypothesis reached by the researcher in the framework of the objectives and research hypotheses and guided by the results of previous studies and what is mentioned in scientific references, the researcher begins to discuss those results as follows:

Shown in Table (7) that the presence of statistical significant differences between pre and post measurements for the experimental group in Pulse rate at rest, Anaerobic Capacity, Carlson Fatigue Curve (Production degree - pulse speed - Level of fitness), Respiratory System Efficiency (FEV1 - FVC) and Anaerobic Efficiency in the direction of post measurement as tabulated " $T$ " value is $(1.761)$ at $(0.05)$ lower than calculated " $T$ " value. The differences were as follows in Pulse rateat rest, calculated "T" value is (16.22) and in Anaerobic Capacity, calculated "T" value is (5.9) and in Carlson Fatigue Curve (Production degree - pulse speed - Level of fitness), calculated " $T$ " value is $(11.78,13.42,16.47)$ and in Respiratory System Efficiency (FEV1 - FVC), calculated "T" value is $(10.85,19.68)$ and in Anaerobic Efficiency, calculated " $T$ " value is (15.46).

Shown in table (8) that the value of (ETA 2) the calculated strength of the impact of the proposed program ranged between $(0.85,0.98)$ and it was greater than $(0.5)$ which shows that the proposed program has a great impact and the established exercises were effective in terms of development of anaerobic capacity and physiological variables. This program was on scientific basis and contains individual and couple workouts in which the muscular work is similar to skill performance requirements and at the same kinetic path which had a great impact on these variables.

These results are supported by improvement percentages as shown in Table No. (8) that there areimprovement percentages in anaerobic capacity and physiological variables between the (pre and post) measurement of the sample members in the direction of the post measurement where the improvement percentages in the pulse rate at rest was (7.5\%), in anaerobic capacity was (8.68\%), in Level of fitness cardiovascular systemwas in production (38.3), in the pulse speed was (17.4), in the level of efficiency $(18.92 \%)$, in vital capacity (FEV1- FVC) was $(33.81 \%, 40.89 \%)$ and in anaerobic efficiency was $(23.46 \%)$.

Improvement in stamina test results reflects the increased ability of the player on the implementation of skills at any time of the game, training on this test also helps to improve the player's anaerobic capacity, as well as the functional status of the heart and cardio-vascular system. This is reflected in the improvementin the time of the return of the pulse after the performance to (120 pulse/min).

The researcher believes that low heart rate at rest in the post measurements is due to the increase of the functional efficiency of the heart muscle as a result of the positive impact of the proposed training program. 
Where Voss Wktian (1998) indicates that the decline in heart rate at rest is one of the most important physiological adaptations resulting from endurance training, which indicates an increase in the efficiency of the heart muscle. (14:319)

Konsleyman (1977) and Ollymor (1982) and Richard et al. (1987) agree that the sport training leads to a decrease in pulse rate at rest and the speed return of the heart to its normal state after effort. (18:124) (35:59) (30:30)

The researcher believes that improvement in post measurements of the anaerobic capacity and physiological variables ofthe sample is due to the high level of adaptation of muscle as a result of training on the physical attributes (under discussion), as well as skill training and competitive wrestling through the proposed training program.

These results are consistent with the study of Mohammed Nassar (2005)(23), Ahmed Sharawy (2002)(6), Ahmed Omara (2003)(1), Sami Abdel Salaam (1996)(32) and Sabry Ali Kotb (2002)(31) which indicated that the program designed to develop these variables leads to their development and improvement.

Through the above, the second hypothesis has been achieved, which indicates the presence of statistically significant differences between the two measurements (pre and post) of the sample members in the anaerobic capacity and physiological variables (under discussion) in the direction of post measuremen

\section{*The conclusions}

In light of the objectives and the nature of this study, within the limits the research sample and the approach used, and the data accumulated by the researcher and the results of the statistical analysis, the researcher reached the following conclusions.

1. The proposed Training Program positively affected the development of stamina in the number of iterations and time to return for $120 \mathrm{n} / \mathrm{s}$ and strength endurance and speed endurance.

2. The proposed training program positively affected the development of anaerobic capacity, pulse rate at rest, the degree of production, rapid pulse, efficiency of respiratory circulatory system, vital capacity and anaerobic efficiency.

\section{* Recommendations}

To the extent that contained in this study of procedures, and the resulting results, the researcher recommends the following:

1-Consideration should be given to the developing of performance during the preparation of wrestlers programs according to scientific principles used in this study and to increase the ability to wrestle efficiently during matches.

2- Consideration should be given to refine coaches by holding training courses for them and teach the coaches all modern training methods.

3-The need to design similar programs for various ages.

4-Consideration should be given to physiological bases of the training process and should be included in the plans, programs and courses for preparation of coaches in the Egyptian Federation of Wrestling, that to identify the physiological aspects associated with wrestling and how they are measured and used. 


\section{*References}

1- Ahmed Abdel Hamid Omara (2003) The impact of the proposed training program for fitness on some physiological variables and defensive attributes for players of the national team of wrestling under 17 years, the physical and athletic science journal, the second edition, the faculty of Physical Education, University of Menoufia.

2, Hussam El dein Mustafa:(2009) Principles of training in wrestling, $\mathrm{Al}$

Wfaa house for the world printing, publishing and distribution, Alexandria.

3- -----------------:(2010)Anaerobic power for wrestlers ,World journal of Sport science, WJSS,Universityo f Tehran.

4-:(2011) The effect of the use of ballistic training on muscle power and the stamina of the players of the national team of Romanian wrestling, scientific journal of Physical Education and athletic College of Physical Education - Helwan University

5- Ahmed Saied Amin (2004): The effect of anaerobic capacity development at some of the physical variables and the level of performance skills of the boxers, PhD Thesis, unpublished, Faculty of Physical Education, Menoufia University.

6-Ahmed Shaarawy Mohamed Ahmed:(2002) The effect of a training program with weights on the effectiveness of the performance for a set of back throw movements and some physiological variables of the beginners wrestlers, Master Thesis, University of Mansoura 7- Al saiedAbdElmaksoud:(1994) athletic training theories - the fundamental aspects of the training, Al kitab center for publication, Cairo, 1994.

8- Al saied Al mohamdykandeel:(2003)A comparative study of the impact of the use of technical skills training for Wrestling (Romanian - free) on the development of some fitness components for juniors, Master Thesis, University of Mansoura.

9- AwisElgibaly:(2000)Sports-training theory and practice, Dar GMs, for printing, Cairo 10- BahaaEldeinIbraheemSalama:(2009)Exercise Physiology first editionDar Al fikr Al arabi Cairo

11-Belal MorsyWitwit:(2005)The development of dynamic response of wrestlers and its impact on the speed of performing the skill of back movement with bending in the legal fighting position, Master Thesis, Faculty of Physical Education, University of Menoufia. $12-$ :(2009)the harmonic capacity and its impact on the kinetic respond to skill of reverse grab from the center of wrestlers, PhD thesis, Faculty of Physical Education, University of Menoufia.

13-Fodor, T.,:(1992)Special Endurance of Wrestlers and the Developmental Methods,MagyarTestnevelesi EgyetemKoezlemnyei, Vol. 2, No.3, pudapest. 14-Foss, M.L. \&Keteyian, S.J.,:(1998)Fox's physiological Basis for Exercise and Sport, $6^{\text {th }}$., ed., McGraw Hill publishing Company, New York

15-Hanafi Mahmoud Mukhtar:(1985)Modern football training, Dar Al FikrAlarabi, Cairo 16-Hassan AbdElsalam Mahfouz:(1994)The impact of the development of stamina on the effectiveness of tactical performance of wrestlers, theories and applications, ver. twenty. 17-Hussien FahmyAbdElzaher:(1993)The effect of a proposed training program on some dimensions of the training situation in wrestling, $\mathrm{PhD}$ thesis, Faculty of Physical Education, Minia University

18-Jamese counsilman:(1977)Competitive swimming , manual, bas coaches , and swimmers, counsilman, co. I.N.C, boosmington, Indiana . 
19-Jarman . S. T. \&Hanly .R.:(1985)Wrestling for beginners Chicago

contemporary books , Inc

20-Martin, W.R. \&Margherita, A.G.,:(1999)Wrestling , phys. Med. Rehabil. N.AM.,Vol.10, No.1, Feb.

21-Mufti IbraheemHammad:(1998)the modern athletic training - Planning - application leadership, Edition 1, Dar Al FikrAlarabi, Cairo.

22-Muhammed BilyIbraheemBily:(2002)proposed training program for the development of anaerobic endurance and its effect to resist the increase of lactic in blood for wrestlers, unpublished Master Thesis, Faculty of Physical Education, University of Menoufia 23Muhammed FathiNassar:(2005)a training program in the light of energy production systems and its effect on the stamina in accordance with the amendments to the law of wrestling, Master Thesis, Faculty of Physical Education, University of Menoufia. 24-Muhammed Hassam Allawy:(1993)Athletic Training Science, Edition 13, Knowledge House, Cairo.

25----------Abu El elaAbdElfattah:(2000)Physiology of Sport Training, Dar Al fikrAlarabi, Cairo.

26-Muhammed RedaElrouby:(1986) The impact of the development of stamina on the effectiveness of the performance of some of back throw movements, unpublished $\mathrm{PhD}$ thesis, Faculty of Physical Education for Boys in Alexandria, Alexandria University 27-Mysnyk, m., Davis, p., Simpson, B.,:(1994)Winning Wrestling Training, Human Kinetics, Chiampaign, IL .

28-Nasser Mustafa MuhammedSayd:(1988)The impact of a proposed program of using circuit training (low-intensity) on the muscular endurance and some physiological variables to the beginner of Romanian wrestling, unpublished Master Thesis, Faculty of Physical Education, Minia University.

29-Peter G.L thomason(1996)Introduction to training theories, International Association of Athletics for amateurs, Regional Development translation Center, Cairo.

30-Richard . Mangi , peter . wiltiam and Dayton:(1987)fitness Sports and Training published, in Theunited states, by pantheam books, Division of Randon house, I .N .c ,NY 31-Sabry Ali KotbMuhammedGhanem:(2002)enzymatic responses associated with the development stamina and its components (strength endurance - speed endurance) for some fall movements on the legs for wrestlers, PhD thesis, Faculty of Physical Education in Alexandria .University of Alexandria.

32-Samy AbdElsalamAbdElatef:(1996)Effect of some aerobic and anaerobic exercises on some physical and physiological variables in wrestling, Master Thesis, Faculty of Physical Education in Port Said, Suez Canal University.

33-Tabata .I et,at:(1998)Effects of moderate-intensity: endurance and high- intensity intermittent traninig on anaerobic capacity and VO2 max, Medicicne and science in sports and exercise physiology and biomechanics nationl institute of fitness sports ,Japan28(10)1327-1330 34-Wageeh Ahmed Shamandy,HassanAbdElsalam Mahfouz(1993): A comparative study of the level of your stamina between high level wrestlers at Arab Republic of Egypt and the Union of the Commonwealth, theories and applications, special edition for the first conference of the Department of exercises and gymnastics.

35-Wilmore, J. ,and David ,L.C.,;(1994 Physiology of Sport and Exercise, Human kinerics. Books, Champaign ,Illinois .. 
